Research Paper

\title{
Research progress in the treatment of small cell lung
}

\section{cancer}

\author{
Yan-fang Qiu*, Zhi-gang Liu ${ }^{* 凶}$, Wen-juan Yang, Yu Zhao, Jiao Tang, Wei-zhi Tang, Yi Jin, Fang Li, Rui \\ Zhong, Hui Wang ${ }^{\bowtie}$
}

Key Laboratory of Translational Radiation Oncology, Hunan Province. Department of Radiation Oncology, Hunan Cancer Hospital and The Affiliated Cancer Hospital of Xiangya School of Medicine, Central South University, Changsha, Hunan, China.

* These authors contributed equally to this work.

$\triangle$ Corresponding authors: Hui Wang, M.D., Department of Radiation Oncology, Hunan Cancer Hospital, The Affiliated Cancer Hospital of Xiangya School of Medicine, Central South University; E-mail: wanghui710327@163.com Fax: 0731-88651999. Zhi-gang Liu, M.D., Ph.D., Department of Radiation Oncology, Hunan Cancer Hospital, The Affiliated Cancer Hospital of Xiangya School of Medicine, Central South University. E-mail: zhigangliu1983@hotmail.com

(C) Ivyspring International Publisher. This is an open access article distributed under the terms of the Creative Commons Attribution (CC BY-NC) license (https://creativecommons.org/licenses/by-nc/4.0/). See http://ivyspring.com/terms for full terms and conditions.

Received: 2016.07.12; Accepted: 2016.09.18; Published: 2017.01.01

\begin{abstract}
Small cell lung cancer (SCLC) accounts for approximately $10-15 \%$ of all lung cancers. No significant improvement has been made for patients with SCLC in the past several decades. The main progresses were the thoracic radiation and prophylactic cranial irradiation $(\mathrm{PCl})$ that improved the patient survival rate. For patients with limited disease and good performance status (PS), concurrent chemoradiotherapy (CCRT) followed by $\mathrm{PCl}$ should be considered. For extensive disease, the combination of etoposide and platinum-based chemotherapy remains the standard treatment and consolidative thoracic radiotherapy is beneficial for patients who have a significant respond to initial chemotherapy. However, the prognosis still remains poor. Recently, efforts have been focused on molecular targets and immunotherapy. But numerous molecular targets methods have failed to show a significant clinical benefit in patients with SCLC. It is anticipated that further development of research will depend on the on-going trials for molecular targeted therapy and immunotherapy which are promising and may improve the outcomes for SCLC in the next decade.
\end{abstract}

Key words: Immunotherapy; Molecular targets; Prophylactic cranial irradiation; Radiotherapy; Small cell lung cancer.

\section{Introduction}

Lung cancer is the leading cause of cancer death worldwide.(1) Small cell lung cancer (SCLC) represented approximately $10-15 \%$ of all lung cancers. $(2,3)$ Smoking is the main risk factor for SCLC, approximately $95 \%$ of these patients were smokers. ${ }^{(4)}$ SCLC is characterized by the low degree of differentiation, shorter doubling time and high sensitivity to chemotherapy and radiotherapy. According to the Veterans' Administration Lung Group, SCLC is currently divided into limited disease (LD) and extensive disease (ED). LD-SCLC, diagnosed in approximately $30-40 \%$ of SCLC patients, is defined as tumor in the side of one chest and coverage within a single radiation field. ED-SCLC, diagnosed in approximately $60-70 \%$ of SCLC patients, is defined as tumor that extends beyond the boundaries of a single radiation field, including distant metastases and malignant pleural effusion. According to the International Association of the Study of Lung Cancer, TNM staging is recommended, based on tumor, node, and metastasis staging, it is useful for the patients who are candidate for surgery. In recent years, treatment of SCLC remains a tremendous challenge for oncologists. The prognosis is still not ideal, with the median survival time ranging from 15 to 20 months for LD-SCLC and 8 to 13 months for ED-SCLC. $(2,5)$

This review aims to summarize the available treatments for SCLC, discussing several issues associated with the timing of radiotherapy (early vs. 
late), radiation dose and fractionation, target volumes, prophylactic cranial irradiation (PCI) and progress in molecular targeted therapy and immunotherapy for SCLC.

\section{Radiotherapy for LD-SCLC}

\section{Timing of Radiation (early vs. late)}

In 1990s, two meta-analyses have shown that chemotherapy combined with definitive thoracic radiation has improved overall survival (OS) compared with chemotherapy alone in LD-SCLC patients. $(6,7)$ Many studies found that CCRT is preferred to sequential chemoradiotherapy. $(8,9)$ Although it has been proven that the concurrent chemoradiotherapy (CCRT) has a significant survival benefit, but the optimal timing of radiotherapy (early vs. late) combined with chemotherapy is still controversial. Most of the studies supported the radiotherapy should be started early after the first or second cycle of chemotherapy.(10,11) Fried et al. systematically reviewed the timing of thoracic radiotherapy for LD-SCLC. Patients received the early radiation (before the third cycle of chemotherapy) had a significant improvement in 2-year OS compared with late radiotherapy (after the beginning of the third cycle of chemotherapy).(10) Also, Pijls-Johannesma et al. showed 5-year OS was significantly higher when radiotherapy was started within 30 days after the start of chemotherapy for SCLC (P=0.02). ${ }^{(11)}$ Recently, a randomized phase III trial of CCRT with either first-cycle or third-cycle chemotherapy showed that late radiotherapy was not inferior to early radiotherapy. No significant difference was found in the median OS (early vs. late, 24.1 vs. 26.8 months; $\mathrm{P}=0.69)$ and median progression-free survival (PFS) (early vs. late, 12.4 vs. 11.2 months; $\mathrm{P}=0.6$ ), but the toxicities in the late radiotherapy group had less grade 3-4 neutropenia.(12) The National Comprehensive Cancer Network (NCCN) recommend that radiotherapy should be started with the first or second cycle of chemotherapy. But it has some limitations. Early CCRT is not suitable for all patients, because most of patients have large volume of the tumor. If the tumor has no obvious shrink after chemotherapy, early radiotherapy may increase the acute or late toxicities.

\section{Radiation Dose and Fractionation}

For LD-SCLC patients, the optimum radiotherapy dose and fractionation have not been established (Table 1). Yee et al. evaluated the radiotherapy dose for LD-SCLC patients who treated with different radiation doses: 54,58, 62 or 65 Gy, respectively, and delivered in 25 daily fractions. The maximal tolerance dose in this trial was 58 Gy.(13)
However, some trials investigated that accelerated hyperfractionated (twice-daily) radiation therapy schedule can improve the outcomes for LD-SCLC patients, which may obtain a better control in the rapidly proliferating small cell tumor.(14-16)

Table 1. Selected radiation dose and fractionation in clinical trials with LD-SCLC.

\begin{tabular}{|c|c|c|c|c|}
\hline Clinical trial & Radiotherapy & Phase & $\begin{array}{l}\text { Median OS } \\
\text { (months) }\end{array}$ & $\begin{array}{l}\mathrm{P} \\
\text { value }\end{array}$ \\
\hline \multirow[t]{2}{*}{ INT 0096(14) } & 45Gy/1.5Gy bid & III & 23 & 0.04 \\
\hline & 45Gy/1.8Gy qd & & 19 & \\
\hline RTOG0239(15) & 61.2Gy $1.8 \mathrm{~Gy}$ qd +1.8Gy bid & II & 20 & \\
\hline \multirow[t]{2}{*}{ Schildet et al.(21) } & 42Gy/1.4Gy bid & II & 25.1 & 0.61 \\
\hline & 45Gy/1.5Gy qd & & 18.8 & \\
\hline \multirow[t]{2}{*}{ EORTC 0807 22) } & 45Gy/1.5Gy bid & III & 25 & 0.15 \\
\hline & 66Gy/2Gy qd & & 30 & \\
\hline
\end{tabular}

INT: Intergroup Trial; RTOG: Radiation Therapy Oncology Group; EORTC: European Organisation for Research and Treatment of Cancer; bid: twice daily; qd: once daily.

The Intergroup Trial 0096 have delivered a total dose of 45 Gy either twice-daily over 3 weeks or once-daily over 5 weeks with CCRT. The twice-daily regimen greatly improved OS compared with once-daily regimen. The main problem seems to be the increase of acute toxicity of grade 3 esophagitis in the twice-daily group ( $27 \%$ vs. $11 \%, \mathrm{P}<0.001) .{ }^{(14)}$ There was an obvious defect of this study, the biologically equivalent dose (BED) in the two groups were different, which may affect the results. In the Radiation Therapy Oncology Group (RTOG) 0239 study, patients with LD-SCLC were given radiation dose to a total of 61.2 Gy over 5 weeks with CCRT. The results showed 2-year OS has no improvement compared with intergroup trial 0096, but the grade 3 esophagitis was significantly lower (18\% vs. $27 \%) .{ }^{(15)}$ A phase II study reported a favorable outcome for LD-SCLC patients with CCRT(30 Gy/20 fraction twice-daily, a 2-week break, and another $30 \mathrm{~Gy} / 20$ fraction twice-daily). For the 76 assessable patients, the median OS was 20 months, 5-year survival rate was $24 \%$, and the toxicities were acceptable.(16) Another study conducted a dose escalation model for LD-SCLC and indicated a treatment of twice-daily with durations of 3 weeks as an optimal schedule.(17) Recently, a randomized phase II trial compared the thoracic radiotherapy of 42 Gy in 15 fractions (twice-daily) with 45 Gy in 15 fractions (once-daily) in 3 weeks. Even though there were no differences in OS, PFS and severe toxicities, the median OS in the twice-daily arm was more than 6 months longer. ${ }^{(18)}$ Higher doses of 60-70 Gy should be delivered in 6 to 7 weeks when using once-daily fraction. ${ }^{(19-21)}$ In order to evaluate the efficiency difference between a total radiation dose 60-70 Gy delivered once-daily with 45 
Gy delivered twice-daily, a clinical trial of EORTC 08072 (CONVERT) reported the median OS in once-daily and twice-daily groups were 25 months and 30 months, respectively ( $\mathrm{P}=0.15)$, the median PFS were 14 months and 15 months, respectively $(\mathrm{P}=0.26)$. The toxicities also have no statistical difference between the two groups. These results supported that the two regimens were suitable for LD-SCLC patients with good PS.(22) Another phase III randomized trial of Cancer and Leukemia Group B (CALGB) 30610/ RTOG 0538 is ongoing (clinicaltrials.gov: NCT00632853). This study evaluated three different radiotherapy schemes for LD-SCLC patients who received 70 Gy delivered once-daily over 7 weeks or 61.2 Gy delivered 1.8 Gy once-daily for first 16 fractions followed by 1.8 Gy twice-daily for last 9 fractions or 45 Gy delivered twice-daily in 3 weeks, respectively. We are looking forward to the results of this clinical trial.

\section{Radiation Target Volume}

Locoregional (LR) failure still plays an important role and the pattern of failure and seems preventable in patients with LD-SCLC. However, reasonable radiation target volume and the use of omitting elective node irradiation (ENI) remain controversial.(23) Although this method is widely used in clinical trials and ordinary treatment, there was still not enough evidence to support the practice of omitting ENI. In 2006, two phase II trials evaluated the patterns of recurrence when patients were treated with omitting ENI based on CT scan radiotherapy.(24,25) Baas et al. reported the results of 36 patients, two patients (5.5\%) was observed isolated nodal failure (INF).(24) Nevertheless, another prospective study found that $26 \%(7 / 27)$ patients developed a local recurrence, $11 \%(3 / 27)$ of them developed INF. The recurrence and failure rates were higher than the expectation. But the small sample size and short follow-up (median 18 months) limited the conclusion in this study.(25) In a retrospective involved-field radiotherapy based on CT scan study with a slightly larger sample size, Xia et al. showed a low rate of INF $(4.6 \%)$, and the recurrence were all limited in the ipsilateral supraclavicular area.(26) These different results are confusing. Inoue et al. have reported that clinical stage based on CT underestimates the nodal stage in $30.6 \%$ compared with the pathologic stage for SCLC patients. (27) Positron emission tomography/computed tomography (PET/CT) has been shown to improve the accuracy in the staging for LD-SCLC patients and could potentially identify involved nodal sites obviously. $(28,29)$ So several studies have evaluated the impact of PET/CT scan on involved nodal irradiation.
These results reported a low rate of INF when omitting ENI was based on PET/CT. (30-33) Van Loon et al. showed that PET-based involved nodal irradiation resulted in a rate of $3 \%$ INF and lower radiation-related toxicities. ${ }^{(30,31)}$ Shirvani et al. showed that only $2 \%$ of patients experienced INF when PET/CT guided omitting ENI.(32) Also for PET-based omitting ENI, Reymen et al. reported similar outcomes and concluded the total gross tumor volume (GTV) was an independent risk factor of survival.(33) Although few studies compared involved nodes irradiation with ENI directly, according to the evidences which verified the safety and efficacy of omitting ENI for SCLC patients, omitting ENI remains the recommend approach in clinical trials and routine treatment.

\section{PCI}

The brain is the most common metastasis sites in SCLC patients, and more than $50 \%$ of patients have found brain metastases.(34) At present, there is no effective treatment for the brain metastasis in SCLC patients. (35) PCI should be considered for patients who have a good response to chemoradiotherapy and do not have metastatic disease to the brain. A retrospective study found that PCI significantly improved the 2 years, 5 years, and 10 years OS compared with those who did not receive PCI for LD-SCLC patients $(\mathrm{P}<0.001) .{ }^{(36)}$ The optimum radiotherapy does and fractionation $\mathrm{PCI}$ still have controversy. Auperin et al. have compared the effect of different total doses (8 Gy, 24 to $25 \mathrm{~Gy}, 30 \mathrm{~Gy}$, and 36 to $40 \mathrm{~Gy}$ ) for SCLC patients indirectly. The reduction rate of brain metastases was $24 \%, 48 \%, 68 \%$ and $73 \%$, respectively. It was found that the higher dose could decrease the risk of brain metastasis, but there was no significant difference in survival.(37) Subsequently, a randomized clinical trial compared the effect of PCI at $25 \mathrm{~Gy} / 10$ fractions vs. $36 \mathrm{~Gy} / 18$ fractions or $36 \mathrm{~Gy} / 24$ fractions for SCLC patients who achieved complete response (CR) or good partial response (PR) after chemoradiation. There was no significant difference in the incidence of brain metastasis between these groups. The incidence rate of brain metastasis in 2 years was $29 \%$ vs. $23 \%$ $(\mathrm{P}=0.18)$. Nonetheless, the 2-year survival was higher in the $25 \mathrm{~Gy} / 10$ fractions group ( $\mathrm{P}=0.05)$. (38) In RTOG 0212 , the results indicated that PCI at a total dose of 36 Gy increased the incidence of chronic neurotoxicity significantly compared with 25 Gy $(P=0.02) .{ }^{(39)}$ A retrospective study also reported that $25 \mathrm{~Gy} / 10$ fractions significantly increased the survival compared with $30 \mathrm{~Gy} / 15$ fractions $(\mathrm{P}=0.018) .{ }^{(40)}$ So $\mathrm{PCI}$ at $25 \mathrm{~Gy} / 10$ fractions should remain the standard 
treatment for LD-SCLC patients with good PS and a good response to initial therapy.

\section{Radiotherapy for ED-SCLC}

\section{Consolidative Thoracic Radiotherapy}

For ED-SCLC patients, the combination of etoposide and platinum-based chemotherapy for four to six cycles remains the standard treatment. ${ }^{(41)}$ However, the prognosis remains poor with the median OS of 8-13 months.(5) Many approaches have been researched to improve the survival. The results demonstrated that consolidative thoracic radiotherapy is beneficial for ED-SCLC patients who have a good respond to chemotherapy (Table 2). A retrospective study demonstrated consolidative thoracic radiotherapy was well tolerated in selected patients with ED-SCLC. The incidence of LR and distant failure in 2 years was $39 \%$ and $74 \%$, respectively. The median OS was 14 months. Most of the patients had minimal acute toxicity and no patients had radiation pneumonitis.(42) In another retrospective review of 119 patients, the addition of thoracic radiotherapy to chemotherapy improved the OS compared with chemotherapy alone for ED-SCLC patients. The overall response rate (ORR) were $86.7 \%$ and $62.7 \%$ in the chemotherapy plus radiotherapy group and chemotherapy alone group, respectively $(\mathrm{P}=0.003)$. In the chemotherapy and radiotherapy group, the median OS, 2-year and 5-year OS rates were 17 months, $35 \%$, and $7.1 \%$, respectively and in the chemotherapy alone group were 9.3 months, $17 \%$, and $5.1 \%$, respectively $(\mathrm{P}=0.014) .{ }^{(43)}$ Yee et al. conducted a prospective non-randomised phase II study, the results demonstrated that consolidative thoracic radiotherapy for ED-SCLC patients were associated with a lower symptomatic thoracic recurrence rate (5/32).(44) Recently, Slotman et al. conducted a phase III randomised controlled trial of 498 patients with ED-SCLC who responded to chemotherapy. The results indicated that there were significantly different between the consolidative thoracic radiotherapy group and the control group. The 2-year OS were $13 \%$ and $3 \% \quad(\mathrm{P}=0.004)$, respectively. The 6 months PFS were $24 \%$ and $7 \%$ $(\mathrm{P}=0.001)$, respectively. ${ }^{(45)}$ These results demonstrated that consolidative thoracic radiotherapy should be considered for selected patients with ED-SCLC with good respond to initial chemotherapy.

\section{PCI}

PCI decreased the incidence of brain metastases and is recommended in patients with LD-SCLC or ED-SCLC who had a good response to initial treatment in previous studies. In a randomized trial from the European Organization for Research on
Treatment of Cancer (EORTC), Slotman et al. assessed 283 patients with ED-SCLC who had response to initial treatment. Patients in the PCI group have reduced the symptomatic brain metastases compared with non-PCI group $(14.6 \%$ vs. $40.4 \%, \mathrm{P}<0.001)$ and increased the median survival (6.7 months vs. 5.4 months, $\mathrm{P}=0.003) .{ }^{(46)}$ However, the interim analysis from a Japanese phase III study investigated the efficacy of PCI for ED-SCLC patients. The results found that PCI group was not superior to non-PCI group, and the median OS of non-PCI group seems to be longer than PCI group (15.1 months vs. 10.1 months, $\mathrm{P}=0.091)$. ${ }^{(47)}$ According to the different results in these studies, the recommendation for PCI might be adjusted in patients with ED-SCLC.

Table 2. Consolidative thoracic radiotherapy in studied with ED-SCLC.

\begin{tabular}{llll}
\hline Author & Therapy & Results & $\begin{array}{l}\text { P } \\
\text { value }\end{array}$ \\
& & & \\
\hline Giuliani et al. (42) & chemotherapy + TRT & 14 months(median OS) & \\
Zhu et al. (43) & $\begin{array}{l}\text { chemotherapy + TRT } \\
\text { chemotherapy along }\end{array}$ & 17 months(median OS) & 0.014 \\
& $\begin{array}{l}\text { chemotherapy + TRT } \\
\text { Yee et al.(44) }\end{array}$ & 8.3 months(median OS) & \\
Slotman et al. (45) & $\begin{array}{l}\text { chemotherapy + TRT } \\
\text { chemotherapy along }\end{array}$ & 3\% (2-year OS) & 0.004 \\
& chear OS) & \\
\hline OS: overall survival. TRT: consolidative thoracic radiotherapy. & &
\end{tabular}

\section{Novel Treatment Strategies of SCLC}

\section{Molecular Targeted Therapy}

The rapid progress of molecular targeted therapy has improved the survival in non-small cell lung cancer (NSCLC) patients. Several methods have been explored in molecular targeted therapy for SCLC (Table 3). There were numerous receptor tyrosine kinases (RTKs) have been studied in SCLC, including epidermal growth factor receptor (EGFR), C-kit and type-1 insulin-like growth factor (IGF-1R).

EGFR mutations mostly occur in lung

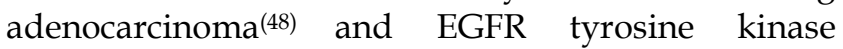
inhibitor (TKIs) have shown clinical benefits compared with chemotherapy in NSCLC patients who were EGFR mutations.(49,50) Only about 4\% patients with EGFR gene mutations in SCLC patients.(51) A previous study suggested that EGFR-TKIs was potentially effective in SCLC with low EGFR expression. ${ }^{(52)}$ However, in a phase II trial, the EGFR-TKIs (gefitinib) failed to demonstrate benefit in 19 patients with relapsed SCLC. It seems that this negative result was caused by the less EGFR mutations in unselected SCLC patients.(53) Interestingly, Sequist et al. reported $14 \%$ patients transformed NSCLC into SCLC who became resistant to EGFR-TKIs and sensitive to standard SCLC therapy. (54) 
Table 3. Selected molecular targeted therapy in clinical trials with SCLC.

\begin{tabular}{|c|c|c|c|c|}
\hline Author & Target & Drugs & Phase & Results \\
\hline Moore et al.(53) & EGFR & Gefitinib & II & $21 \%$ (1-year OS) \\
\hline \multirow[t]{2}{*}{ Dy et al.(56) } & C-kit & Imatinib & II & Arm Aa: 3.9 months (median OS) \\
\hline & & & & Arm Bb: 5.3 months (median OS) \\
\hline \multirow[t]{2}{*}{ Spigel et al.(57) } & C-kit & Imatinib & II & 8.4 months (median OS) \\
\hline & & & & 5.4 months (median PFS) \\
\hline \multirow[t]{2}{*}{ Schneider et al.(58) } & C-kit & Imatinib & II & 7.8 months (median OS) \\
\hline & & & & 4.3 months (median PFS) \\
\hline \multirow[t]{2}{*}{ Miller et al.(59) } & C-kit & Dasatinib & II & 17.0 weeks (median OS) \\
\hline & & & & 5.9 weeks (median PFS) \\
\hline Ellis et al.(62) & IGF-1R & Dalotuzumab & I & 67\% (ORR) \\
\hline Belani et al.(63) & IGF-1R & $\mathrm{EP}$ vs. $\mathrm{EP}+\mathrm{V}$ vs. $\mathrm{EP}+\mathrm{Cixutumumab}$ & II & 9.1 vs. 9.8 vs. 10.1 months (median OS, $\mathrm{P}<0.05$ ) \\
\hline \multirow[t]{2}{*}{ Spigel et al.(64) } & VEGF & Bevacizumab & II & 12.1 months (median OS) \\
\hline & & & & 9.13 months (median TTP) \\
\hline \multirow[t]{2}{*}{ Ready et al.(65) } & VEGF & Bevacizumab & II & 11.6 months (median OS) \\
\hline & & & & 7.0 months (median PFS) \\
\hline \multirow[t]{2}{*}{ Jalal et al.(66) } & VEGF & Bevacizumab & II & 30.0 weeks (median OS) \\
\hline & & & & 14.7 weeks (median PFS) \\
\hline \multirow[t]{2}{*}{ Trafalis et al.(67) } & VEGF & Bevacizumab & II & 6.0 months (median OS) \\
\hline & & & & 3.0 months (median PFS) \\
\hline \multirow[t]{2}{*}{ Marcello et al.(68) } & VEGF & Bevacizumab + EP/EC vs. EP/EC & III & 8.9 vs. 9.8 months (median OS, $\mathrm{P}=0.113$ ) \\
\hline & & & & 5.7 vs. 6.7 months (median PFS, $P=0.03$ ) \\
\hline \multirow[t]{2}{*}{ Han et al.(69) } & VEGF & Sunitinib & II & 5.6 months (median OS) \\
\hline & & & & 1.4 months (median PFS) \\
\hline Sharma et al.(70) & VEGF & Sorafenibin & II & 7.4 months (median OS) \\
\hline \multirow[t]{2}{*}{ Arnold et al.(71) } & VEGF & Vandetanib vs. placebo & II & 10.6 vs. 11.9 months (median $\mathrm{OS}, \mathrm{P}=0.90$ ) \\
\hline & & & & 2.7 vs. 2.8 months (median PFS, $\mathrm{P}=0.51$ ) \\
\hline \multirow[t]{2}{*}{ Ramalingam et al.(72) } & VEGF & Cediranib & II & 6.0 months (median OS) \\
\hline & & & & 2.0 months (median PFS) \\
\hline Lee et al. ${ }^{(73)}$ & VEGF & $\mathrm{EC}+$ Thalidomide vs. EC + placebo & II & 10.1 vs. 10.5 months (median $O S, P=0.28$ ) \\
\hline Owonikoko et al.(76) & PARP1 & Veliparib + EP & I & $71.4 \%$ (ORR) \\
\hline Maria et al.(77) & PARP1 & TMZ + Veliparib vs. TMZ + placebo & II & 8.2 vs. 7.0 months (median OS, $\mathrm{P}=0.50$ ) \\
\hline Charles et al.(80) & DLL3 & Rova-T & II & 8.0 months (median OS) c \\
\hline \multicolumn{5}{|c|}{$\begin{array}{l}\text { EGFR: epidermal growth factor receptor; PFS: progress free } \\
\text { growth factor; TTP: time to progression; EP: etoposide-cispla } \\
\text { ligand 3; Rova-T: Rovalpituzumab tesirine; } \\
\text { a Disease progression < } 3 \text { months after previous treatment. }\end{array}$} \\
\hline \multicolumn{5}{|c|}{ bisease progression $\geq 3$ months after previous treatment. } \\
\hline
\end{tabular}

The expression of C-kit and its ligand stem cell factor are high in SCLC.(55) Many studies have investigated the imatinib, an inhibitor of C-kit for SCLC patients. Unfortunately, the results of these clinical trials were disappointing that imatinib did not improve the outcomes in SCLC. ${ }^{(56-58)}$ Dasatinib is another inhibitor of C-kit. A phase II trial of dasatinib in 45 patients with chemotherapy sensitive relapsed SCLC. The results indicated the efficacy did not reach the specified criteria and the trial was terminated. Lack of C-kit mutations gene in SCLC may be the reason for the negative results. (59)

The IGF-1R is commonly over-expressed in lung cancer and under investigation in SCLC.(60) IGF-1R targeting can increase the efficacy of chemotherapy and radiotherapy in SCLC.(61) Currently, some clinical trials about the IGF-1R tyrosine kinase inhibitors are carrying out in SCLC, such as linsitinib (OSI-906, clinicaltrials.gov:NCT00887159), and humanized monoclonal antibodies, dalotuzumab (MK-0646,
clinicaltrials.gov:NCT00869752) and cixutumumab (IMC-A12, clinicaltrials.gov:NCT1533181). A phase I trial demonstrated that the toxicities of dalotuzumab (MK-0646) combined with standard chemotherapy of cisplatin/etoposide in ED-SCLC was accepted, but the addition of dalotuzumab to chemotherapy did not bring a clinically improvement in ORR (67\%) compared standard chemotherapy alone. (62) In a randomized phase II trial, chemotherapy plus concurrent and maintenance cixutumumab compared with chemotherapy alone for ED-SCLC patients. The results showed that there was no significant improvement in efficacy between the groups.(63)

Angiogenesis is an important pathogenetic mechanism of disease progression in SCLC and vascular endothelial growth factor (VEGF) is a key mediator in angiogenic pathways. Several trials have studied the relationships between VEGF and SCLC. Bevacizumab, a humanized monoclonal antibody against VEGF has been evaluated for SCLC patients. 
In some phase II studies, bevacizumab combined with standard chemotherapy showed efficacy as a first line treatment in ED-SCLC.(64, 65) But the results of bevacizumab combined with paclitaxel as a second line treatment did not improve outcomes in relapsed chemotherapy sensitive SCLC.(66) However, a phase II study of bevacizumab plus irinotecan demonstrated low toxicity and promising efficacy in relapsed chemotherapy resistant SCLC.(67) A phase III randomized trial was assessed the efficacy of cisplatin-etoposide with or without bevacizumab as the first-line treatment in ED-SCLC. Even though the addition of bevacizumab to chemotherapy leads to a statistically significant improvement in PFS, but there was not statistically significant improvement in the OS.(68) Other anti-angiogenic agents have been assessed the safety and efficacy in SCLC, such as sunitinib, sorafenib, vandetanib, cediranib, thalidomide. (69-73) However, these agents did not indicate promising outcomes. Further researches should be warranted in the area of angiogenesis therapy of SCLC.

Targeting the DNA repair seems to be a novel therapeutic for SCLC patients. Poly-(ADP-ribose) polymerase 1 (PARP1), a DNA repair protein, has been studied recently. Lauren et al. reported that the PARP1 inhibitor was a potential target and efficacious in a preclinical testing in SCLC. ${ }^{(74)}$ Talazoparib (BMN 673 ) is a highly potent PARP inhibitor. Sensitivity to talazoparib was associated with the expression levels of DNA repair proteins and the baseline activation of the PI3K/Mtor (PAM) pathway for SCLC.(75) In a phase I study, veliparib (a PARP inhibitor) combined with cisplatin and etoposide showed safety and efficacy in ED-SCLC. (76) For relapsed SCLC patients, a phase II study comparing temozolomide (TMZ) plus either veliparib or placebo as second or third-line therapy. The preliminary result indicated that response rate was higher with veliparib/TMZ compared to TMZ alone (39\% vs. $14 \%, \mathrm{P}=0.016)$. But the median $O S$ has no difference between the veliparib arm and placebo arm $(\mathrm{P}=0.50)$. Hematologic toxicity more commonly occurred in the veliparib/TMZ arm. (77)

The Notch signaling pathway is an important pathway related to not only stem cell biology but also cancer. ${ }^{(78)}$ Delta-like ligand 3 (DLL3) protein is a part of the Notch signaling pathway and inhibiting tumor initiating (stem) cells which is expressed on the surface of tumor cells. A DLL3-targeted antibody-drug conjugate (ADC), rovalpituzumab tesirine (Rova-T; SC16LD6.5), effectively targets and eradicates the level expression of DLL3-expressing in SCLC.(79) Charles et al. reported the results of single-agent Rova-T in recurrent or refractory SCLC.
$25 \%(15 / 61)$ patients achieved PR or CR, and 72\% (44/61) achieved clinical benefit (best response of at least stable disease). For the patients who have available archive tissue specimens, among them $\geq$ $50 \%$ of cells expressing DLL3, 12/22 (55\%) achieved PR or CR, and 20/22 (91\%) achieved clinical benefit. The median OS was 8 months. Rova-T demonstrated encouraging efficacy and safety in recurrent or refractory SCLC. ${ }^{(80)}$

Tarextumab (OMP-59R5) is a fully human monoclonal antibody that inhibits the Notch 2/3 receptors. In a phase Ib study, tarextumab combined with etoposide and platinum chemotherapy in ED-SCLC demonstrated a promsing outcome, with 13 of 16 patients (81.3\%) achieved PR and 3 (18.8\%) achieved stable disease. ${ }^{(81)} \mathrm{A}$ phase II study is carrying out (ClinicalTrials.gov:NCT01859741).

\section{Immunotherapy}

Recently, immunotherapy is becoming a promising strategy of treatment in various solid tumors. Therefore, a large number of trials are focused on immunotherapy in SCLC patients (Table 4).

Several tumor vaccines have been investigated in SCLC, but they may have limited efficacy. BEC2 is a monoclonal antibody that targets ganglioside antigen GD3 which is highly expressed in SCLC. In the early clinical trial, Grant et al. evaluated the BEC2 and Bacillus Calmette-Guerin (BCG) vaccine therapy after standard treatment in SCLC, and the results showed a longer survival and relapse-free survival than previous study of similar patients. ${ }^{(82)}$ Based on these promising results, a phase III trial was conducted to evaluate the adjuvant vaccination with BEC2 plus BCG in responding patients with LD-SCLC. The median OS in the observation group and vaccination group was 16.4 and 14.3 months $(\mathrm{P}=0.28)$, respectively. The OS failed to achieve significant difference. However, in the subgroup of analysis among vaccinated patients $(n=55)$, the median survival of humoral responders showed a trend of improvement compared with non-responders (19.2 vs. 13.9 months; $\mathrm{P}=0.0851)$. ${ }^{(83)}$ A study of 29 patients who had received p53 vaccine combined with chemotherapy treatments in ED-SCLC showed a high ORR. Despite a response to p53 cancer vaccine in this study, the optimal treatment may not take vaccination as single modality. It should be combined with chemotherapy directly. ${ }^{(84)} \mathrm{A}$ phase I/II study reported that the p53-modified adenovirus-tranduced dendritic cell vaccine (INGN-225) was well tolerated and induced in a significant immune response $(40-50 \%) .(85)$ 
Table 4. Selected immune therapy in clinical trials with SCLC.

\begin{tabular}{|c|c|c|c|c|}
\hline Author & Target & Drugs & Phase & Results \\
\hline Grant et al. ${ }^{(82)}$ & Vaccine & $\mathrm{BEC} 2 / \mathrm{BCG}$ & II & 11 months (median RFS) for ED-SCLC \\
\hline Giaccone et al.(83) & Vaccine & BEC2/BCG vs. observation & III & 14.3 vs. 16.4 months (median $\mathrm{OS}, \mathrm{P}=0.28$ ) \\
\hline Antonia et al.(84) & Vaccine & P53 & I & 11.8 months (median OS) \\
\hline Chiappori et al.(85) & Vaccine & INGN-225 & $\mathrm{I} / \mathrm{II}$ & 8.8 months (median OS) \\
\hline Zarogoulidis et al.(86) & & $\begin{array}{l}\text { CT vs. } C T+\text { IFN- } \alpha \text { vs. } \\
\text { CT + IFN- } \gamma \text { vs. } C T+I F N-\alpha+I F N-\gamma\end{array}$ & II & $\begin{array}{l}19.0 \text { vs. } 34.0 \text { vs. } 17.0 \text { vs. } 13.6 \text { months } \\
\text { (median OS, } P<0.05 \text { ) for LD-SCLC }\end{array}$ \\
\hline Pillai et al.(87) & & IFN & II & $\begin{array}{l}6.2 \text { months (median OS) } \\
2.0 \text { months (median PFS) }\end{array}$ \\
\hline Ott et al.(93) & PD-1 & Pembrolizumab & I & $35 \%$ (ORR) \\
\hline Antonia et al.(95) & PD-1/CTLA-4 & Nivolumab $1 \mathrm{mg} / \mathrm{kg}+$ Ipilimumab $3 \mathrm{mg} / \mathrm{kg}$ & $\mathrm{I} / \mathrm{II}$ & $23 \%$ (ORR) \\
\hline Reck et al.(97) & CTLA-4 & d Control vs. Concurrent Ipilimumab vs. Phased Ipilimumab & II & $\begin{array}{l}9.9 \text { vs. } 9.1 \text { vs. } 12.9 \text { (median OS) } \\
5.3 \text { vs. } 5.7 \text { and } 6.4 \text { (median irPFS) }\end{array}$ \\
\hline
\end{tabular}

BCG: Bacillus Calmette-Guerin; RFS: relapse-free survival; ED-SCLC: extensive disease small cell lung cancer; CT: chemotherapy; LD-SCLC: extensive disease small cell lung cancer; IFN: Interferon; PD-1: programmed death-1; CTLA-4: cytotoxic T-lymphocyte antigen-4; irPFS: immune-related progression-free survival.

d Control (paclitaxel-carboplatin + Ipilimumab + placebo); concurrent Ipilimumab (Ipilimumab+ paclitaxel-carboplatin followed by placebo + paclitaxel-carboplatin); Phased Ipilimumab (placebo + paclitaxel-carboplatin followed by Ipilimumab+ paclitaxel-carboplatin).

Interferon (IFN) was one of the first immunotherapies cytokines to be studied in anticancer. A phase II, randomized study evaluated the effect of IFN in SCLC, a total of 164 patients with SCLC were assigned to four groups as follows: chemotherapy alone, or a combination of chemotherapy and IFN (IFN- $\alpha$, IFN- $\gamma$, IFN- $\alpha$ plus IFN- $\gamma$ ). The results showed a significant survival benefit for chemotherapy plus IFN- $\alpha$ compared with chemotherapy alone $(\mathrm{P}<0.05) .{ }^{(86)}$ But an Eastern Cooperative Oncology Group (ECOG) 6501 study showed the addition of IFN-a and 13-cis-retinoic to paclitaxel did not improve the outcomes for recurrent SCLC patients. ${ }^{(87)}$ So we need further trials to verify the role of the IFN- $\alpha$ as a potential therapy in patients with SCLC.

Immune checkpoint inhibitors offer wider application in various solid tumors such as melanoma, head and neck, NSCLC, and bladder carcinomas. ${ }^{(88-91)}$ The results of these inhibitors demonstrated this treatment was more beneficial than vaccines for SCLC in the last few years. ${ }^{92}$ ) The immune checkpoint receptors are antigen independent and down-regulate T-cell including the programmed death-1 (PD-1), programmed death ligand-1 (PD-L1) and cytotoxic T-lymphocyte antigen-4 (CTLA-4).

PD-1 is the major immune checkpoint receptor that inhibits T-cell activation and regulates immunosuppression through binding of its ligand, PD-L1. Pembrolizumab is an anti-PD-1 monoclonal antibody that blocks the PD-1/PD-L1 pathway. In the Keynote 028 trial, the interim analysis reported that 24 patients with ED-SCLC received the pembrolizumab who had progressed on chemotherapy and expression of PD-L1. The ORR was 35\% and durable responses were more than 16 weeks. However, the drug related adverse event rate was 53\%.(93) The safety and efficacy of pembrolizumab for PD-L1 positive patients with SCLC were similar to other carcinoma. Ishii et al. conducted a study to investigate the expression of PD-L1 in 102 patients of SCLC that was evaluated by immunohistochemical analysis. $71.6 \%$ of SCLC patients expressed PD-L1 and was significantly correlated with LD-SCLC. The median OS was 16.3 months in the PD-L1-positive group and 7.3 months in the PD-L1-negative group $(\mathrm{P}<0.001) .{ }^{94)}$ Some prospective clinical trials are investigating pembrolizumab plus chemotherapy or pembrolizumab plus chemotherapy and radiotherapy for SCLC patients (ClinicalTrials.gov:NCT02359019 and NCT02403920). We expect the results of these combination treatment to be beneficial for SCLC patients. In addition, a phase I/II clinical trial of nivolumab (anti-PD-1 monoclonal antibody) combined with or without ipilimumab (anti-CTLA-4 monoclonal antibody) for treatment of recurrent SCLC. The results presented that nivolumab plus ipilmumab and nivolumab alone showed beneficial effect to SCLC and the adverse events were tolerable. ${ }^{(95)} \mathrm{A}$ phase III clinical trial of nivolumab or nivolumab plus ipilimumab in SCLC should be carrying out.

CTLA-4 is another well-studied immune checkpoint protein that expressed on activated T cells whose function is to down-regulate T-cell activity.(96) A randomized phase II study reported the ipilimumab combined with paclitaxel and carboplatin as the first-line treatment in ED-SCLC. The results demonstrated that phased ipilimumab (chemotherapy plus placebo followed by ipilimumab plus chemotherapy) improved PFS compared with concurrent ipilimumab plus chemotherapy followed by chemotherapy plus placebo $(\mathrm{P}=0.03)$, and OS were 12.5 months and 9.1 months, respectively, with a trend of improvement although there was no 
significant differences between the two groups $(\mathrm{P}=0.13) .{ }^{(97)}$ Based on these results, a randomized phase III clinical trial of ipilimumab plus chemotherapy compare with chemotherapy alone in ED-SCLC patients is ongoing (ClinicalTrials.gov: NCT01450761).

\section{Conclusions}

In summary, the main progresses were the chemoradiotherapy and PCI improved the survival for SCLC patients in the past decades. Recently, investigators focus on the molecular targeted therapy and immunotherapy. The preliminary results showed some little therapeutic breakthroughs from some clinical trials. We expect these treatment strategies can improve the outcomes for SCLC.

\section{Acknowledgments}

This work was partially supported by National Natural Science Foundation of China (Grant No. 81472802, NO. 81201982, NO. 81572500); Oncology Department (National Health and Family Planning Commission of the PRC 2013/544); China Hunan Provincial Science \&Technology Fund (NO.2013SK2017); Hunan Young Talents (NO. 2016RS3036).

\section{Conflict of Interest}

There authors have no conflict of interest.

\section{References}

1. Siegel RL, Miller KD, Jemal A: Cancer statistics, 2015. CA Cancer J Clin. 2015; 65:5-29.

2. Van Meerbeeck JP, Fennell DA,De Ruysscher DK. Small cell lung cancer. Lancet. 2011; 378(9804):1741-1755.

3. Byers LA, Rudin CM: Small cell lung cancer: Where do we go from here? Cancer. 2015; 121:664-672.

4. Pesch B, Kendzia B, Gustavsson P, et al. Cigarette smoking and lung cancer--relative risk estimates for the major histological types from a pooled analysis of case-control studies. Int I Cancer 2012; 131:1210-1219.

5. Lally BE, Urbanic JJ, Blackstock AW, et al. Small cell lung cancer: have we made any progress over the last 25 years? Oncologist. 2007; 12(9): 1096-1104.

6. Pignon, JP, Arriagada R, Ihde DC, et al. A meta-analysis of thoracic radiotherapy for small-cell lung cancer. N Engl J Med. 1992; 327: 1618-24.

7. Warde P, Payne D. Does thoracic irradiation improve survival and local control in limited-stage small-cell carcinoma of the lung? A meta-analysis. J Clin Oncol. 1992; 10:890-95.

8. Stinchcombe TE, Gore EM. Limited-stage small cell lung cancer: current chemoradiotherapy treatment paradigms. Oncologist. 2010; 15:187-195.

9. Herbst RS, Heymach JV, Lippman SM. Lung cancer. N Engl J Med. 2008; 359:1367-80.

10. Fried DB, Morris DE, Poole C, et al. Systematic review evaluating the timing of thoracic radiation therapy in combined modality therapy for limited- stage small-cell lung cancer. J Clin Oncol. 2004; 22:4837-4845.

11. Pijls-Johannesma M, De Ruysscher D, Vansteenkiste J, et al. Timing of chest radiotherapy in patients with limited stage small cell lung cancer: A systematic review and meta-analysis of randomised controlled trials. Cancer Treat Rev. 2007; 33:461-473

12. Sun JM, Ahn YC, Choi EK, et al. Phase III trial of concurrent thoracic radiotherapy with either first- or third-cycle chemotherapy for limited-disease small-cell lung cancer. Ann Oncol. 2013; 24(8):2088-2092.

13. Yee D, Hanson J, Butts C, et al. Phase I dose escalation trial of hypofractionated limited-field external beam thoracic radiotherapy for limited-stage small cell carcinoma of the lung. Radiother Oncol. 2010; 96(1):78-83.

14. Turrisi AT, 3rd, Kim K, Blum R, et al. Twice-daily compared with once-daily thoracic radiotherapy in limited small-cell lung cancer treated concurrently with cisplatin and etoposide. N Engl J Med. 1999; 340:265-271.
15. Komaki R, Paulus R, Ettinger DS, et al. Phase II study of accelerated high-dose radiotherapy with concurrent chemotherapy for patients with limited small-cell lung cancer: Radiation Therapy Oncology Group protocol 0239. Int J Radiat Oncol Biol Phys. 2012; 83:e531-6.

16. Schild SE, Bonner JA, Hillman S, et al. Results of a phase II study of high-dose thoracic radiation therapy with concurrent Cisplatin and etoposide in limited-stage small-cell lung cancer. J Clin Oncol. 2007; 25(21):3124-9.

17. Arvidson NB, Khuntia D, Tomé WA. Dose escalation model for limited stage small cell lung cancer. Radiother Oncol. 2009; 91(3):379-385

18. Grønberg $\mathrm{BH}$, Halvorsen $\mathrm{TO}$, Fløtten $\varnothing$, et al. Randomized phase II trial comparing twice daily hyperfractionated with once daily hypofractionated thoracic radiotherapy in limited disease small cell lung cancer. Acta Oncol. 2016; 55(5):591-7.

19. Miller KL, Marks LB, Sibley GS, et al. Routine use of approximately $60 \mathrm{~Gy}$ once-daily thoracic irradiation for patients with limited-stage small-cell lung cancer. Int J Radiat Oncol Biol Phys. 2003; 56:355-359.

20. Roof KS, Fidias P, Lynch TJ, et al. Radiation dose escalation in limited-stage small-cell lung cancer. Int J Radiat Oncol Biol Phys. 2003; 57:701-708.

21. Bogart JA, Herndon JE, Lyss AP, et al. 70 Gy thoracic radiotherapy is feasible concurrent with chemotherapy for limited-stage small-cell lung cancer: analysis of Cancer and Leukemia Group B study 39808. Int J Radiat Oncol Biol Phys. 2004; 59:460-468.

22. Corinne FF, Michael Snee, Linda Ashcroft, et al. (CONVERT: An international randomised trial of concurrent chemo-radiotherapy (cCTRT) comparing twice-daily (BD) and once-daily (OD) radiotherapy schedules in patients with limited stage small cell lung cancer (LS-SCLC) and good performance status (PS). J Clin Oncol. 2016; 34 (Suppl):abstr8504.

23. V Videtic GM, Belderbos JS, Spring Kong FM, et al. Report from the International Atomic Energy Agency (IAEA) consultants' meeting on elective nodal irradiation in lung cancer: small-cell lung cancer (SCLC). Int J Radiat Oncol Biol Phys. 2008; 72: 327-34.

24. Baas P, Belderbos JS, Senan S, et al. Concurrent chemotherapy (carboplatin, paclitaxel, etoposide) and involved-field radiotherapy in limited stage small cell lung cancer: a Dutch multicenter phase II study. Br J Cancer. 2006; 94(5): $625-3$

25. De Ruysscher D, Bremer R, Koppe F, et al. Omission of elective node irradiation on basis of CT-scans in patients with limited disease small cell lung cancer: a phase II trial. Radiother Oncol. 2006; 80:307-1.

26. Xia B, Chen GY, Cai XW, et al l. Is involved-field radiotherapy based on CT safe for patients with limited-stage small-cell lung cancer? Radiother Oncol. 2012; 102(2):258-62.

27. Inoue M, Miyoshi S, Yasumitsu T, et al. Surgical results for small cell lung cancer based on the new TNM staging system. Thoracic Surgery Study Group of Osaka University, Osaka, Japan. Ann Thorac Surg. 2000; 70:1615-9.

28. Brink I, Schumacher T, Mix M, et al. Impact of [18F] FDG-PET on the primary staging of small-cell lung cancer. Eur J Nucl Med Mol Imaging. 2004; 31: 1614-20.

29. Bradley JD, Dehdashti F, Mintun MA, et al. Positron emission tomography in limited-stage small-cell lung cancer: a prospective study. J Clin Oncol. 2004; 22: 3248-54.

30. van Loon J, Offermann C, Bosmans G, et al. 18FDG-PET based radiation planning ofmediastinal lymph nodes in limited disease small cell lung cancer changesradiotherapy fields: a planning study. Radiother Oncol. 2008; 87: 49-54.

31. van Loon J, De Ruysscher D, Wanders R, et al. Selective nodal irradiation on basis of (18) FDG-PET scans in limited-disease small-cell lung cancer: a prospective study. Int J Radiat Oncol Biol Phys. 2010; 77(2): 329-36.

32. Shirvani SM, Komaki R, Heymach JV, et al. Positron emission tomography/computed tomography-guided intensity-modulated radiotherapy for limited-stage small-cell lung cancer. Int J Radiat Oncol Biol Phys. 2012; 82(1): e91-7.

33. Reymen B, Van Loon J, van Baardwijk A, et al. Total gross tumor volume is an independent prognostic factor in patients treated with selective nodal irradiation for stage I to III small cell lung cancer. Int J Radiat Oncol Biol Phys. 2013; 85(5): 1319-24.

34. Blanchard P, Le Pechoux C. Prophylactic cranial irradiation in lung cancer. Curr Opin Oncol. 2010; 22(2):94-101.

35. Lekic M, Kovac V, Triller N, et al. Outcome of small cell lung cancer (SCLC) patients with brain metastases in a routine clinical setting. Radiol Oncol. 2012; 46(1):54-59.

36. Patel S, Macdonald OK, Suntharalingam M. Evaluation of the use of prophylactic cranial irradiation in small cell lung cancer. Cancer. 2009; 115:842-850.

37. Auperin A, Arriagada R, Pignon JP, et al. Prophylactic cranial irradiation for patients with small-cell lung cancer in complete remission. Prophylactic Cranial Irradiation Overview Collaborative Group. N Engl J Med. 1999; 341:476-484

38. Le Pechoux C, Dunant A, Senan S, et al. Standard-dose vs higher-dose prophylactic cranial irradiation (PCI) in patients with limited stage small-cell lung cancer in complete remission after chemotherapy and thoracic radiotherapy (PCI 99-01, EORTC 22003-08004, RTOG 0212, and IFCT 99-01): a randomised clinical trial. Lancet Oncol. 2009; 10:467-474.

39. Wolfson $\mathrm{AH}, \mathrm{Bae} \mathrm{K}$, Komaki R, et al. Primary analysis of a phase II randomized trial Radiation Therapy Oncology Group (RTOG) 0212: Impact of different total doses and schedules of prophylactic cranial irradiation on 
chronic neurotoxicity and quality of life for patients with limited-disease small-cell lung cancer. Int J Radiat Oncol Biol Phys. 2011; 81:77-84.

40. Schild SE, Foster NR, Meyers JP, et al. Prophylactic cranial irradiation in small-cell lung cancer: findings from a North Central Cancer Treatment Group Pooled Analy sis. Ann Oncol. 2012; 23:2919-2924.

41. Sundstrom S, Bremnes RM, Kaasa S, et al. Cisplatin and etoposide regimen is superior to cyclophosphamide, epirubicin, and vincristine regimen in small-cell lung cancer: results from a randomized phase III trial with 5 years' follow-up. J Clin Oncol. 2002; 20:4665-4672.

42. Giuliani ME, Atallah S, Sun A, et al. Clinical outcomes of extensive stage small cell lung carcinoma patients treated with consolidative thoracic radiotherapy. Clin Lung Cancer. 2011; 12: 375-79.

43. Zhu H, Zhou Z, Wang Y, et al. Thoracic radiation therapy improves the overall survival of patients with extensive-stage small cell lung cancer with distant metastasis. Cancer. 2011; 117: 5423-31.

44. Yee D, Butts C, Reiman A, et al. Clinical trial of post-chemotherapy consolidation thoracic radiotherapy for extensive-stage small cell lung cancer. Radiother Oncol. 2012; 102: 234-38.

45. Slotman BJ, van Tinteren H, Praag JO, et al. Use of thoracic radiotherapy for extensive stage small cell lung cancer: a phase 3 randomised controlled trial. Lancet. 2015; 385: 36-42.

46. Slotman B, Faivre-Finn C, Kramer G, et al. Prophylactic cranial irradiation in extensive small-cell lung cancer. N Engl J Med. 2007; 357:664-672.

47. Seto T, Takahashi T, Yamanaka T, et al. Prophylactic cranial irradiation (PCI) has a detrimental effect on the overall survival (OS) of patients (pts) with extensive disease small cell lung cancer (ED-SCLC): Results of a Japanese randomized phase III trial. J Clin Oncol ASCO Ann Meet Abstr. 2014; 32:7503.

48. Gong Y, Pao W. EGFR mutant lung cancer. Curr Top MicrobiolImmunol. 2012; 355:59-81.

49. Mok TS, Wu YL, Thongprasert S, et al. Gefitinib or carboplatin-paclitaxel in pulmonary adenocarcinoma. N Engl J Med. 2009; 361:1-11.

50. Rosell R, Carcereny E, Gervais R, et al. Erlotinib vs standard chemotherapy as first-line treatment for European patients with advanced EGFR mutation-positive non-small cell lung cancer (EURTAC): a multicentre, open-label, randomized phase 3 trial. Lancet Oncol. 2012; 13:239-246.

51. Tatematsu A, Shimizu J, Murakami Y, et al. Epidermal growth factor receptor mutations in small cell lung cancer. Clin Cancer Res. 2008; 14:6092-6.

52. Tanno S, Ohsaki Y, Nakanishi K, et al. Small cell lung cancer cells express EGFR and tyrosine phosphorylation of EGFR is inhibited by gefitinib ("Iressa", ZD1839). Oncol Rep. 2004; 12:1053-1057.

53. Moore AM, Einhorn LH, Estes D, et al. Gefitinib in patients with chemo-sensitive and chemo-refractory relapsed small cell cancers: a Hoosier Oncology Group phase II trial. Lung Cancer. 2006; 52:93-97.

54. Sequist LV, Waltman BA, Dias-Santagata D, et al. Genotypic and histological evolution of lung cancers acquiring resistance to EGFR inhibitors. Sci Transl Med. 2011; 3:75ra26

55. Hibi K, Takahashi T, Sekido $Y$, et al. Coexpression of the stem cell factor and the c-kit genes in small-cell lung cancer. Oncogene. 1991; 6: 2291-2296.

56. Dy GK, Miller AA, Mandrekar SJ, et al. A phase II trial of imatinib (STI571) in patients with c-kit expressing relapsed small-cell lung cancer: a CALGB and NCCTG study. Ann Oncol. 2005; 16:1811-1816.

57. Spigel DR, Hainsworth JD, Simons L, et al. Irinotecan, carboplatin, and imatinib in untreated extensive-stage small-cell lung cancer: a phase II trial of the Minnie Pearl Cancer Research Network. J Thorac Oncol. 2007; 2:854-861.

58. Schneider BJ, Kalemkerian GP, Ramnath N, et al. Phase II trial of imatinib maintenance therapy after irinotecan and cisplatin in patients with c-Kit-positive, extensive-stage small-cell lung cancer. Clin Lung Cancer. 2010; 11:223-227.

59. Miller AA, Pang H, Hodgson L, et al. A phase II study of dasatinib in patients with chemosensitive relapsed small cell lung cancer (Cancer and Leukemia Group B 30602). J Thorac Oncol. 2010; 5:380-384.

60. Badzio A, Wynes MW, Dziadziuszko R, et al. Increased insulin-like growth factor 1 receptor protein expression and gene copy number in small cell lung cancer. J Thorac Oncol. 2010; 5:1905-11.

61. Ferte $\mathrm{C}$, Loriot $\mathrm{Y}$, Clemenson $\mathrm{C}$, et al. IGF-1R targeting increasesthe antitumor effects of DNA-damaging agents in SCLC model: anopportunity to increase the efficacy of standard therapy. Mol Cancer Ther. 2013; 12:1213-22.

62. Ellis PM, Shepherd FA, Laurie SA, et al. NCIC CTG IND.190 phase I trial of dalotuzumab (MK-0646) in combination with cisplatin and etoposide in extensive-stage small-cell lung cancer. J Thorac Oncol. 2014; 9(3):410-3.

63. Belani $\mathrm{CP}$, Dahlberg SE, Rudin CM, et al. Three-arm randomized phase II study of cisplatin and etoposide (CE) vs CE with either vismodegib (V) or cixitumumab $(\mathrm{Cx})$ for patients with extensive-stage small cell lung cancer (ES-SCLC) (ECOG 1508). J Clin Oncol. 2013; 31(15S):460s; abstract 7508.

64. Spigel DR, Greco FA, Zubkus JD, et al. Phase II trial of irinotecan, carboplatin, and bevacizumab in the treatment of patients with extensive-stage small-cell lung cancer. J Thorac Oncol. 2009; 4(12):1555-1560.

65. Ready NE, Dudek AZ, Pang HH, et al. Cisplatin, irinotecan, and bevacizumab for untreated extensive-stage small-cell lung cancer: CALGB 3306, a phase II study. J Clin Oncol. 2011; 29:4436-4441.

66. Jalal S, Bedano P, Einhorn L, et al. Paclitaxel plus bevacizumab in patients with chemosensitive relapsed small cell lung cancer: a safety, feasibility, and efficacy study from the Hoosier Oncology Group. J Thorac Oncol. 2010; 5(12):2008-2011
67. Trafalis DT, Alifieris C, Stathopoulos GP, et al. Phase II study of bevacizumab plus irinotecan on the treatment of relapsed resistant small cell lung cancer. Cancer Chemother Pharmacol, 2016; 77(4):713-22.

68. Marcello Tiseo, Luca Boni, Francesca Ambrosio, et al. Italian multicenter phase III randomized study of cisplatin-etoposide with or without bevacizumab as first-line treatment in extensive stage small cell lung cancer (SCLC): GOIRC-AIFA FARM6PMFJM trial. J Clin Oncol. 2016; 34(suppl):abstr8513.

69. Han JY, Kim HY, Lim KY, et al. A phase II study of sunitinib inpatients with relapsed or refractory small cell lung cancer. Lung Cancer. 2013; 79:137-42.

70. Sharma N, Pennell N, Nickolich M, et al. Phase II trial of sorafenibin conjunction with chemotherapy and as maintenance therapyin extensive-stage small cell lung cancer. Investig New Drugs. 2014; 32:362-8.

71. Arnold AM, Seymour L, Smylie M, et al. Phase II study of vandetanib or placebo in small-cell lung cancer patients after complete or partial response to induction chemotherapy with or without radiation therapy: National Cancer Institute of Canada Clinical Trials Group Study BR.20. J Clin Oncol. 2007; 25:4278-4284.

72. Ramalingam S, Belani CP, Mack PC, et al. Phase II study of Cediranib (AZD 2171), an inhibitor of the vascular endothelial growthfactor receptor, for second-line therapy of small cell lung cancer (National Cancer Institute \#7097). J Thorac Oncol. 2010; 5:1279-84.

73. Lee SM, Woll PJ, Rudd R, et al. Anti-angiogenic therapy using thalidomide combined with chemotherapy in small cell lung cancer: a randomized, double-blind, placebo controlled trial. J Natl Cancer Inst. 2009; 101:1049-1057.

74. Byers LA, Wang J, Nilsson MB, et al. Proteomic profiling identifies dysregulated pathways in small cell lung cancer and novel therapeutic targets including PARP1. Cancer Discov. 2012; 2:798-811.

75. Cardnell RJ, Feng Y, Diao L, et al. Proteomic markers of DNA repair and PI3K pathway activation predict response to the PARP inhibitor BMN 673 in small cell lung cancer. Clin Cancer Res. 2013; 19:6322-8.

76. Owonikoko TK, Dahlberg SE, Khan SA, et al A phase I safety study of veliparib combined with cisplatin and etoposide in extensive stage small cell lung cancer: A trial of the ECOG-ACRIN Cancer Research Group (E2511). Lung Cancer. 2015; 89:66-70.

77. Maria $\mathrm{CP}$, Lee $\mathrm{MK}$, Saiama NW, et al, A multi-center, randomized, double-blind phase II study comparing temozolomide (TMZ) plus either veliparib (ABT-888), a PARP inhibitor, or placebo as 2nd or 3rd-line therapy for patients (Pts) with relapsed small cell lung cancers (SCLCs). J Clin Oncol. 2016; 34 (suppl; abstr 8512)

78. Penton AL, Leonard LD, Spinner NB. Notch signaling in human development and disease. Semin Cell Dev Biol. 2012; 23:450-7.

79. Saunders LR, Bankovich AJ, Anderson WC, et al. A DLL3-targeted antibody-drug conjugate eradicates high-grade pulmonary neuroendocrine tumor-initiating cells in vivo. Sci Transl Med. 2015; 7(302):302ra136.

80. Charles M R, Maria CP, Todd MB, et al. Safety and efficacy of single-agent rovalpituzumab tesirine (SC16LD6.5), a delta-like protein 3 (DLL3)-targeted antibody-drug conjugate (ADC) in recurrent or refractory small cell lung cancer (SCLC). J Clin Oncol. 2016; 34 (suppl): abstrLBA8505.

81. Pietanza MC, Spira AI, Jotte RM, et al. Final results of phase Ib of tarextumab (TRXT, OMP-59R5, anti-Notch2/3) in combination with etoposide and platinum (EP) in patients (pts) with untreated extensive stage small cell lung cancer (ED-SCLC). J Clin Oncol. 2015; 33(suppl):abstr7508.

82. Grant SC, Kris MG, Houghton AN, et al. Long survival of patients with small cell lung cancer after adjuvant treatment with the anti-idiotypic antibody BEC2 plus Bacillus Calmette-Guerin. Clin Cancer Res. 1999; 5:1319-23.

83. Giaccone G, Debruyne C, Felip E, et al. Phase III study of adjuvant vaccination with Bec2/bacille Calmette-Guerin in responding patients with limited-disease small cell lung cancer (European Organisation for Research and Treatment of Cancer 08971-08971B; Silva Study). J Clin Oncol. 2005; 23:6854-64.

84. Antonia SJ, Mirza N, Fricke I, et al. Combination of p53 cancer vaccine with chemotherapy in patients with extensive stage small cell lung cancer. Clinical cancer research. 2006, 12: 878-87.

85. Chiappori AA, Soliman H, Janssen WE, et al. INGN-225: a dendritic cell-based p53 vaccine (Ad.p53-DC) in small cell lung cancer: observed association between immune response and enhanced chemotherapy effect. Expert opinion on biological therapy. 2010; 10: 983-91.

86. Zarogoulidis $\mathrm{K}$, Ziogas E, Boutsikou E, et al. Immunomodifiers in combination with conventional chemotherapy in small cell lung cancer: a phase II, randomized study. Drug Des Devel Ther. 2013; 7: 611-617.

87. Pillai RN, Aisner J, Dahlberg SE, et al. Interferon alpha plus 13-cis-retinoic acid modulation of BCL-2 plus paclitaxel for recurrent small-cell lung cancer (SCLC): an Eastern Cooperative Oncology Group study (E6501). Cancer Chemother. Pharmacol. 2014; 74(1):177-183.

88. Brahmer JR, Tykodi SS, Chow LQ, et al. Safety and activity of anti-PD-L1 antibody in patients with advanced cancer. N Engl J Med. 2012; 366: 2455-2465.

89. Topalian SL, Hodi FS, Brahmer JR, et al. Safety, activity, and immune correlates of anti-PD-1 antibody in cancer. N Engl J Med. 2012; 366:2443-2454.

90. Sznol M, Chen L. Antagonist antibodies to PD-1 and B7-H1 (PD-L1) in the treatment of advanced human cancer. Clin Cancer Res. 2013; 19:1021-1034.

91. Rizvi NA, Hellmann MD, Snyder A, et al. Cancer immunology. Mutational landscape determines sensitivity to PD-1 blockade in non-small cell lung cancer. Science. 2015; 348:124-128.

92. Spigel DR, Socinski MA. Rationale for chemotherapy, immunotherapy, and checkpoint blockade in SCLC. J Thorac Oncol. 2013; 8:587-98. 
93. Ott PA, Fernandez MEE, Hiret S, et al. Pembrolizumab (MK-3475) in patients with extensive-stage small cell lung cancer: Preliminary safety and efficacy results from KEYNOTE-028. J Clin Oncol. 2015; 33(15S):400s; abstract 7502115.

94. Ishii $\mathrm{H}$, Azuma K, Kawahara A, et al 1. Significance of programmed cell death-ligand 1 expression and its association with survival in patients with small cell lung cancer. J Thorac Oncol. 2015; 10(3):426-30.

95. Antonia SJ, López-Martin JA, Bendell J, et al. Nivolumab alone and nivolumab plus ipilimumab in recurrent small-celllung cancer (CheckMate 032): a multicentre, open-label, phase 1/2 trial. Lancet Oncol. 2016; 17(7):883-95.

96. Salama AK, Hodi FS. Cytotoxic T-lymphocyte-associated antigen-4. Clin Cancer Res, 2011; 17:4622-4628.

97. Reck M, Bondarenko I, Luft A, et al. Ipilimumab in combination with paclitaxel and carboplatin as first-line therapy in extensive disease-small-cell lung cancer: results from a randomized, doubleblind, multicenter phase 2 trial. Ann Oncol. 2013; 24:75-83. 